\title{
EDUCAÇÃO HISTÓRICA E HISTORIOGRAFIA EM UM MUNDO SEM FRONTEIRAS.
}

\section{HISTORICAL EDUCATION AND HISTORIOGRAPHY IN A WORLD WITHOUT BORDERS.}

\section{Estevão C. de Rezende Martins ${ }^{1}$}

\section{RESUMO}

A educação histórica, no século 21, necessita lidar com o manejo da cultura histórica em um ambiente mundial mais e mais globalizado. A historiografia inovadora recente oferece pistas de reflexão para os que operam a educação histórica (docentes) e seu público, na relação entre história nacional e história mundial.

Palavras-chaves: Educação histórica; cultura histórica; globalização; história nacional; história mundial.

\begin{abstract}
Historical education, in the 21st century, needs to deal with historical culture in a more and more globalized world environment. Recent innovative historiography offers avenues for reflection for those who operate historical education (teachers) and their public, in the relationship between national history and world history.
\end{abstract}

Keywords: Historical education; historical culture; globalization; national history; world history.

\section{Introdução}

Aprender e ensinar História é uma prática individual e social humana com longa trajetória. Lidar com a experiência do tempo pela reflexão, de modo a compreender a historicidade da existência é um 'ponto de agenda' de qualquer ser humano. 0 esforço de qualificar racionalmente a vida prática se constitui numa estratégia fundante da consciência histórica de toda pessoa e de sua identidade. Esse processo constante da vida prática humana é conhecido de forma ampla, contemporaneamente, sob o nome de 'educação histórica' (MARTINS, 2019).

Pensar historicamente consiste pois numa prática intelectual que acompanha a formação da pessoa humana e lhe faculta situar a si e a seu mundo no fluxo do tempo. 0 pensamento histórico

\footnotetext{
${ }^{1}$ Professor Titular emérito da Universidade de Brasília (UnB) echarema@gmail.com
} 
e a consciência histórica são como frente e verso da mesma moeda. 0 pensamento é a operação reflexiva ativa e a consciência é a resultante consolidada da identidade do sujeito. Como nenhum ser humano surge em um mundo sem história, o meio-ambiente natural e cultural em que o pensamento é efetivado e a consciência instituída e consolidada está, por conseguinte, igualmente impregnado historicamente. Natureza e cultura, assim, encontram-se, no agente racional humano, no ambiente comum da cultura histórica.

Nessa cultura aprende-se e ensina-se história. Nessa cultura investiga-se, elabora-se também a versão científica da reflexão história, na história como ciência.

Assim, ensinar e aprender fazem parte indissociável de um mesmo processo de constituição de sentido do agir no tempo, em particular de sua conexão com o que havia ontem e com o que há hoje, que - juntos - são indispensáveis para explicar o quê e porquê haverá isso ou aquilo amanhã. Em tempo: é preciso levar em consideração que o 'amanhã', nesse contexto, é sempre o que acontece depois, na sequência de uma situação atual qualquer. Futuro não é necessariamente só o que ocorre dias, semanas, meses, anos ou séculos mais tarde. Futuro é sempre, inicialmente, o projeto de configuração do tempo por vir, por causa do tempo que é e do tempo que foi. De futuro passa a presente, e de presente se torna passado. A cada instante. Um moto contínuo na vida humana e em sua cultura. Somente uma 'dobradinha' aprender-ensinar, como é a educação histórica, pode constituir uma experiência suficientemente desafiadora para conhecer o(s) acontecimento(s), dissecá-lo(s), confrontar-se com ele(s), torná-lo(s) referência cognitiva, consciencial, cultural a título pessoal como coletivo.

Os tempos presentes dos grupos sociais e de seus integrantes inspiram, suscitam, provocam, causam, pois, em um processo de formação recíproco, a reflexão historicizante que leva à constituição de sentido pela e na consciência. No quadro das instituições formais de ensino, sob as condições contemporâneas (embora não necessariamente recentes ou novas), o processo é induzido pelas práticas escolares consagradas, decididas ou impostas (segundo as circunstâncias sociais, culturais, econômicas, políticas). A educação histórica, que organiza o passado para responder à(s) demanda(s) surgidas no presente (e por causa do presente), tem uma função notável: a de ensinar, instruir, prover informação de maneira a produzir compreensão, de modo formal ou informal. Exerce, pois, a função clássica da orientação: $\delta$ เ $\delta$ ó $\sigma \kappa \omega$.

Desde meados do século 18 e até os dias de hoje, a historiografia buscou dar voz a três vertentes fundamentais da experiência do tempo vivida e refletida pelos homens. Essas vertentes são: a experiência pessoal do tempo, a reflexão sobre experiência do tempo na consciência histórica, a crítica da experiência do tempo refletida e legada por outros.

A experiência do tempo, vivida, exprime a noção de que cada agente racional humano faz história. De fato, todo agente faz história e é por ela feito. Como ninguém do gênero humano nasce em um mundo sem história, cada agente se defronta com a realidade empírica, concreta, do que foi feito e legado por outros. Essa realidade está marcada pelo ritmo do tempo: passado, presente e futuro. Todo movimento desse ritmo é sempre, de certa forma, esses três momentos simulta- 
neamente - todo futuro é o presente subsequente a um passado e todo passado é o presente anterior a um futuro. A espiral do tempo histórico resulta de um processo de interação individual e social dos homens e por certo também o produz. Tal interação tem um efeito prático notável: ela educa - ou seja, ela conduz o agente a tomar consciência de seu mundo e de sua cultura, e a assenhorear-se de ambos, de forma que o resultado seja conhecido e consciente como história.

Como os indivíduos, culturalmente, são formados gradual e longamente, os projetos educacionais não podem negligenciar o problema decorrente da imposição de conteúdos e de formas de pensar e de agir. A institucionalização jurídica e política contemporânea é extremamente extensiva e aparentemente só faz expandir ainda mais os processos de padronização (centralização, homogeneização) instaurados desde o advento, em meados do século 15, da forma de Estado moderno.

Cruzadas as evoluções da precedência cultural histórica (o legado histórico é o capital intelectual inicial de todo sujeito) e da institucionalização dominante do Estado (a estrutura estatal tem prioridade organizacional de fato e de direito), resultou, em particular ao longo do século 19 (mesmo com a variável interveniente da constitucionalização) e ao longo do século 20 (mesmo com as variáveis intervenientes da democratização e dos direitos humanos), a consolidação de processos 'formatadores' (mesmo se não necessários em si) que tendem a dar a vantagem ao impacto cultural sobre os indivíduos.

Esforços para modificar tal prevalência costumam ser chamados de 'revolucionários' (em graus diversos de 'radicalidade') e seus mecanismos de composição (modificações, complementações, supressões do legado cultural e político) são descritos como 'reformistas'. O embate (ou a rivalidade) entre propostas maximalistas (tudo que conste da herança cultural deve ser substituído ou suprimido) e propostas reformistas (mantenha-se tudo o que dá certo e altere-se o que estiver ultrapassado) é constante.

Esse embate exprime uma espécie de conflito entre gerações e uma forma de 'reinventar' o mundo a partir de si, a cada vez, em repetidas versões solipsistas de interesse individual ou coletivo (real ou pretendido). De uma ou de outra forma domina a pretensão de cada um alçar-se, mediante a cultura e seu processo de produção e conservação, para acima e para além do 'capital inicial' de sua emergência em um mundo historicamente concreto. Alçar-se acima e além de si foi por vezes considerado como um abuso de orgulho do ser humano, na mais clássica tradição prometeica. Querer ir além de sua contingência, em uma tentativa de divinização (que Freud chama de 'deus protético'), é uma aventura e um risco, quando não uma utopia. No entanto, malgrado a aparência de um esforço vão, a constituição de uma cultura histórica, sempre em expansão e acumulação, parece ser uma tarefa a que todo e cada indivíduo, em todo e qualquer tempo, se dedica. Toda essa asserção de si em um mundo sobre o qual age, porque sobre ele reflete, implica ter consciência de sua cultura história e entender o quanto "meu mundo" está em um "mundo de todos" - particular e universal ao mesmo tempo (e no mesmo tempo - por exemplo, em pleno século 21). 


\section{História mundial como a história do mundo globalizado.}

A história mundial ou global é a história contemporânea no sentido de reflexão consciente sobre a própria história e um reposicionamento no contexto mundial. Em que medida a nova história mundial difere das anteriores? Há desígnios históricos universais, comuns?

A discussão sobre a história mundial ou global apenas começou a se firmar na cena historiográfica desde os anos 1990. 0 debate é intenso e o alcance da pesquisa requerida é vasto. No século 21 o volume de dados a pesquisar, compilar, analisar, interpretar e comparar é vastíssimo (OSTERHAMMEL, 2012). Debate-se a relação entre indivíduos e 'meio-ambiente cultural'. Tornou-se imperativo estar ciente das complexidades da globalização e da complexidade do presente, sem esquecer as características da respectiva história nacional (regional, local) mas necessariamente em perspectiva que inclua o horizonte mais amplo do 'além das fronteiras", tanto geopolíticas como culturais.

É preciso, pois, introduzir novas orientações na reflexão 'nacional": levar em contar a história transnacional e a mundial. A nova 'história mundial' se diferencia das anteriores na medida em que deixar de lado a ideia de "potência, cultura, economia hegemônica' - prevalecente durante longas décadas - e busca entender a trama da história global como um mosaico interativo, em que entre o tamanho das peças pode variar, mas que só faz sentido se for considerado que todas as peças têm lugar e importância.

\subsection{Inovação metódica}

O domínio da história nacional foi amplamente dominante até a década de 1960. Isso corresponde à tradição da ciência histórica, cuja cientificização no século 19 se fundamentou basicamente no Estado-nação. Toda narrativa histórica incluía uma ideia do "mundo", encapsulada na "peça" própria de história nacional. Michael Geyer, em 2005, falou da história nacional pensada e ensinada como uma espécie de "contêiner", definido pela experiência nacional-centrada, na qual o "resto do mundo" entra se e quando convém às dimensões do contêiner (do "palco" próprio) (GEYER, 2005).

Nesse "palco" atuam entidades personificadas, que interagem umas com as outras, como se fossem sujeitos: "O Brasil perpetua as injustiças e a pobreza"; "A Europa protege seu mercado agrícola"; "Os Estados Unido são egoístas"; "A Alemanha declara guerra à França"; "A Inglaterra se sente ameaçada pela expansão da frota alemã"; "O terrorismo islâmico é uma ameaça universal", e assim por diante. Contar a história em geral como "variável dependente" de uma história nacional tem uma longa e persistente tradição. A história nacional, para onde quer que você olhe, é essencialmente "a" história por excelência até hoje, isto é, o tipo de história que "naturalmente" se impõe à consciência das pessoas.

As características evidentes de uma história nacional politicamente orientada (mas não a história nacional per se) foram criticadas pela história social a partir do final dos anos 1960 e, posteriormente, perderam pelo menos um pouco de sua legitimidade por meio de uma série de novas abordagens: história dos marginalizados, história das mulheres, história de gênero, histó- 
ria da vida cotidiana e, nos Estados Unidos, sobretudo por meio de 'histórias étnicas' e, portanto, por aquelas abordagens que hoje em dia amiúde são chamadas de história cultural. Nesse processo, a ciência histórica se pluralizou. No lugar da "história" vieram as "histórias", e acordou abruptamente do "nobre sonho" da objetividade histórica (NOVICK, 1988). Nos estudos históricos, a história nacional política não é mais automaticamente a história-padrão, ou seja, história que é primariamente "inicializada" na consciência.

O que é a 'história mundial' (global, universal) e a que ela pode servir? Logo de início pode-se reafirmar, com Jörn Rüsen (2015), que ela responde a carências de orientação. Ou melhor: à carência de orientação diante da aceleração das mudanças no tempo. Essas carências são tão dependentes das circunstâncias históricas quanto da experiência pessoal. Se ficar claro que os fenômenos não podem mais ser explicados com os paradigmas convencionais, começa a busca por novos esquemas de orientação. "A 'verdadeira' história de uma geração é a tolice das próximas gerações", escreve o historiador americano Ross Dunn (2000).

Após a implosão da esfera de influência soviética em 1989 e após os atentados terroristas de 11 de setembro de 2001, é evidente a necessidade de redesenhar a história em termos de história mundial, mais precisamente: como história global. Da multiplicidade de livros e artigos que respondem aos novos desafios, alguns merecem destaque por apresentarem novas abordagens explicativas de forma particularmente produtiva. "1989" é o quadro de referência para o historiador Charles Maier (2000), professor de Harvard, que delineou novas conceituações da cultura da memória em um artigo notável na American Historical Review. Eric Hobsbawm também respondeu às condições historicamente alteradas de 1989 não apenas com seu livro A era dos extremos (1994), mas também com seu autobiográfico Interesting Times (2002) ou ainda com Fractured Times: Culture and Society in the 20th Century (2013). Dan Diner $(1999,2003)$ abriu novos caminhos na Alemanha e propôs uma perspectiva histórica global a partir de uma perspectiva do Leste Europeu.

Charles Maier, por exemplo, descreve as mudanças na memória das atrocidades do século 20, conforme foram lembradas insistentemente desde 1990. A virada epocal da queda do muro de Berlim em 1989 permitiu expandir a consciência de que traumas do passado que causaram grande impacto, como o Holocausto e o Gulag, mesmo historicamente 'passados', ainda continuam a desempenhar um papel importante na memória das pessoas, bem como na cultura da memória das nações. Segundo Maier, o futuro pertence à memória pós-colonial com todas as injustiças e todos os traumas que podem ser sentidos até os dias de hoje, decorrentes do colonialismo dos séculos 19 e 20 (e mesmo de antes) e que são cada vez mais fortes nos protestos étnicos, tanto nas sociedades ocidentais como internacionais. Eric Hobsbawm e Dan Diner analisam o que este último chamou de "guerra civil mundial do século 20" com "sua retórica ruidosa de universais conflitantes", daí os desígnios mundiais do capitalismo liberal e do bolchevismo, esses grandes adversários da Guerra Fria. Hobsbawm adiciona sua experiência pessoal ao catastrófico século 20: uma experiência que muitas vezes deixava poucas opções e ao mesmo tempo exigia decisões 
importantes, não menos pessoais.

Finalmente, há outro autor que viajou o mundo por dois anos para compreender as mudanças dramáticas que estão ocorrendo em nossa vida: Manuel Castells. Castells, em sua fascinante obra em três volumes $A$ Era da Informação, oferece não apenas a admirável inovação crítica de nossos sistemas de comunicação, mas também o caráter singular das novas guerras e da nova diferenciação da pobreza, tanto local como global, que ele chama de "quarta mundialização". Seus livros, escritos entre 1996 e 1998, são notáveis, principalmente em vista da previsão do aumento global dos ataques terroristas poucos anos antes de 11 de setembro de 2001 (CASTELLS, 19992008).

Esses trabalhos são tentativas bem-sucedidas de encontrar respostas para as novas necessidades de orientação do presente em uma era de emaranhados globais. Para uma discussão sobre a história mundial ou sobre as perspectivas globais de compreensão histórica no contexto europeu, eles oferecem valiosos pontos de partida.

\subsection{Conceitos de história mundial e global}

Quando falamos de "história mundial", temos que explicar o que queremos dizer com isso, a fim de evitar a suposição de que se trata de uma conexão com os esboços históricos universais do Iluminismo. A nova história mundial tem pouco em comum com eles. A história universal europeia, cujos princípios Friedrich Schiller expôs em sua aula inaugural, "0 que é chamado de história universal e com que finalidade é ela estudada" de 1789, presumia que a história era um processo orientado para um objetivo que levaria à melhoria da condição humana.

A história universal era uma espécie de teologia secularizada, uma abordagem progressiva que só poderia ser compreendida a partir do horizonte de tempo do século 18. De acordo com suas raízes na filosofia iluminista, a história tinha propósito, missão e direção. 0 objetivo era melhorar a sociedade; perseguia a missão de trazer os princípios da cultura e da filosofia ocidentais para mais perto do mundo, o que se esperava que resultasse em um progresso geral na história humana. Nessa concepção, a Europa era o centro indiscutível e claramente definido. A relação entre o centro e a periferia estava claramente definida para cada pessoa educada, e o mundo não se apresentava tão desesperadamente descentrado como é hoje. A questão da agência, sobre a competência para atuar na história, também foi claramente esclarecida: o mundo consistia em homens pensantes (brancos), agindo racionalmente, em vez de, como é o caso hoje, pessoas que agem de forma complexa e estão sujeitas a demandas diversas, muitas vezes contraditórias, que podem ser de qualquer gênero, etnia ou diferença.

Esses princípios estruturais, comprometidos com o Iluminismo, podem ser rastreados até as teorias da modernização da década de 1960, cuja característica decisiva foi sua orientação eurocêntrica. As teorias da modernização passaram - o que fica bem claramente explicitado no modelo de patamares de progresso econômico de Walt W. Rostow (1960) - de um modelo de desenvolvimento mais ou menos esquemático, que supostamente perpassaria todos os países e que necessariamente levaria à democratização com base em um sólido crescimento econômico. 
Bruce Mazlish (1988) enunciou a diferença entre as teorias da modernização e a história global da seguinte forma: "A modernização foi basicamente uma imposição ocidental. A globalização, em contraste, é um processo universal, onde uma nova 'civilização' (...) está sendo criada (para melhor ou para pior) por inúmeros participantes (...)." Com o passar do tempo, as teorias da modernização foram substituídas por modelos de transformação diferenciados e por várias tentativas de determinar empiricamente o processo de globalização.

Em suma, isso quer dizer: o que distingue o mundo antigo ou esboços históricos universais, em sua maioria ancorados no Iluminismo e nas visões de mundo eurocêntricas, dos esforços atuais são três pressuposições. Em primeiro lugar, a construção de um sujeito histórico atuante ou de sujeitos coletivos atuantes. Em segundo lugar, a suposição apodítica de que a Europa é o centro e o resto do mundo a periferia. Em terceiro lugar, a noção de que o processo histórico resulta mais ou menos automaticamente em progresso, modernização, democracia e uma ordem mundial razoável.

Como o novo mundo ou história global difere dos antigos designs históricos universais? A terminologia nem sempre é clara, mas muitos autores fazem uma distinção entre história mundial e história global. "História mundial" muitas vezes significa "toda a história do mundo inteiro", uma forma de história mundial que Jürgen Osterhammel (1998) corretamente descreveu como uma forma superior de loucura que só leva a "colagens pouco convincentes de dados". A "história global", por outro lado, se concentra na análise de como se formou o contexto mundial em diferentes épocas históricas, por exemplo, no início do período moderno (ver o "sistema mundial" de Immanuel Wallerstein), no século 19 (a disseminação do capitalismo e da colonização), na segunda metade e no final do século 20. 0 contexto mundial emergente global é discutido por sociólogos sob o título "sociedade mundial" (WOBBE, 2000).

O tema "história mundial" está crescendo nos EUA e tem alterado a ênfase metódica na pesquisa. Ross Dunn (2000) distingue entre o "modelo da herança ocidental", o "modelo da diferença cultural" e o "modelo da mudança de padrões". 0 primeiro geralmente leva a um "desfile de civilizações". O zelo missionário pelo estilo de vida americano é persistente e aparece nos cursos de "civilização ocidental", representando uma abordagem de "civilização ocidental como história mundial", dentro da estrutura conceitual que conduz ao temido "choque de civilizações" à maneira de Samuel Huntington. Assim o objetivo é defender e desenvolver os valores universalistas únicos do Ocidente contra outras civilizações (especialmente as islâmicas). 0 "modelo da diferença cultural" surgiu dos movimentos sociais das décadas de 1960 e 1970. É culturalmente relativista. Na prática, significa que também são levadas em consideração as culturas não ocidentais, que são conceituadas como basicamente equivalentes. A agenda secreta deste tipo de história mundial (ou seu objetivo declarado) é transmitir mais informações sobre a África, Ásia e América Latina em termos quantitativos e menos sobre a Europa e os EUA em termos percentuais, a fim de evitar o eurocentrismo inerente à nossa visão da história. A terceira abordagem, que Dunn chama de "modelo de padrões de mudança", é a que atualmente domina o debate da história mundial ame- 
ricana e que inclui os grandes do debate da história mundial nos EUA: William McNeill, Leften Stavrianos, Philip Curtin, Jerry Bentley, Patrick Manning, C.A. Bayly, Peter Stearns, Carol Gluck, Charles Bright e Michael Geyer. Este modelo, também defendido por Ross Dunn, segue a ideia de que os campos da pesquisa histórica devem ser abertos e flexíveis, mas não determinados por categorias culturais convencionais. 0 "modelo da mudança de padrões (...) promove a ideia de que os campos sociais e espaciais da investigação histórica devem ser abertos e fluidos, não predeterminados por categorias culturais convencionalmente supostas". 0 modelo está aberto a questões de intencionalidade, agência e contingência em contextos globais.

\section{Apreendendo fenômenos "emergentes".}

Certamente é correto que os historiadores enfatizem que o que é tratado hoje sob o título de globalização não é necessariamente novo, mas que existiram contextos mundiais ou mesmo um "sistema mundial" (Wallerstein) desde o início do período moderno, no mais tardar. Mas certamente existem desenvolvimentos que são realmente novos para o século 20, mais precisamente em sua segunda metade, e que constituem um contexto mundial especificamente inédito. Esses desenvolvimentos não funcionam em contextos mundiais gerais, ou, como Ross Dunn e William McNeill chamam, "zonas interativas" de séculos anteriores ou não podem ser adequadamente apreendidos como tais. Manuel Castells elaborou uma lista impressionante do que há de novo na história mundial: o que é novo são os computadores, a internet e a revolução nas tecnologias de comunicação com as consequentes mudanças nos padrões de comunicação. Hoje consideramos as letras digitadas em máquinas de escrever mecânicas como relíquias de tempos passados, e as simplificações logísticas feitas pela internet levam a uma multiplicação de tarefas e a uma aceleração crescente do trabalho mecânico e intelectual. Também novos são os movimentos sociais desde o último terço do século 20, que em particular mudaram de forma duradoura a posição social de homens e mulheres e suas relações entre si.

Outra novidade são as demandas fundamentalmente alteradas sobre a força de trabalho descritas de maneira impressionante por Richard Sennett (2006) - e uma composição da força de trabalho que muda drasticamente. 0 modelo do ganha-pão exclusivamente masculino está se tornando cada vez menos importante, e a proporção de mulheres e minorias na população trabalhadora aumentou acentuadamente e em proporções sem precedentes, pelo menos nos Estados Unidos, onde as tendências podem ser mais pronunciadas do que na Europa. No entanto, a tendência também pode ser observada na Europa. No geral, a produtividade do trabalho aumentou, o que significa que o trabalho (e, consequentemente, a renda do trabalho) está se tornando uma mercadoria cada vez mais escassa em todo o mundo. Como consequência das mudanças nas condições de trabalho, as relações geracionais também mudam. Atualmente, experimenta-se isso em muitos países europeus, como a reestruturação e o desmantelamento dos sistemas de seguridade social. Nas últimas três a quatro décadas, uma revolução cultural não só relativizou hierarquias convencionais há muito consideradas invioláveis, mas também promoveu novas formas de ob- 
tenção de conhecimento ou daquilo que é considerado conhecimento (padronizado, canônico). 0 conhecimento canônico das gerações anteriores está cada vez mais sob a pressão da legitimação. Como resultado, os requisitos para a educação da próxima geração mudaram significativamente. Novos conteúdos e novas formas de aquisição de conhecimento estão se tornando cada vez mais importantes.

Outra novidade é que a migração transnacional aumentou significativamente em escala global. Os movimentos migratórios mais fortes ocorrem no continente africano, não na Europa, América do Norte ou Austrália. Também é novidade que a maior parte da população mundial está concentrada em metrópoles ou megacidades, com tendência de crescimento. Até recentemente, a maior parte da humanidade vivia no campo e em aldeias. Novas formas de desigualdade regional e global estão aumentando, em alguns casos dramaticamente. As relações comerciais internacionais e os vínculos econômicos globais não excluem mais nenhuma região do mundo. Os mercados financeiros operam globalmente e o capitalismo está cada vez mais desenfreado em todo o mundo. As consequências para a capacidade de direção da política tornam-se claras. 0 encolhimento do setor público e a (re)privatização de funções anteriormente públicas podem ser observados em todo o mundo. Isso pode ser visto no crescimento das instituições educacionais privadas (escolas, universidades) e na privatização dos serviços sociais. Até mesmo as prisões já estão sendo privatizadas nos Estados Unidos, e há um número crescente de mercenários modernos ao redor do mundo que estão fora do controle público. Se o monopólio estatal do uso legítimo da força é minado e os serviços públicos convertidos em serviços privados, isso leva a uma deslegitimação dramática da política.

Até aqui os fatores arrolados por Castells. 0 progresso na corrida espacial, os satélites na estratosfera, a fissão nuclear e os perigos resultantes contra os quais os Estados territoriais não podem proteger seus cidadãos (bomba atômica; Chernobyl) e problemas ambientais como buracos na camada de ozônio ou aquecimento global são fenômenos históricos que não podem ser referidos sem mais a uma globalização que estaria sendo observada há séculos, mas que são de fato fenômenos historicamente novos. Esses pontos revelam os contornos de um mundo que se globaliza na atualidade. Eles elencam possíveis tópicos de uma história global ou mundial que se torna cada vez mais importante.

Quando as pessoas hoje falam de "um só mundo" - um uso da linguagem que está começando a substituir as ideias predominantes de um primeiro, segundo e terceiro mundo - é sinal de uma percepção crescente das conexões históricas mundiais e das novas conexões resultantes. No entanto, também existe um eufemismo na ideia de "um só mundo". Sim, estamos lidando com um mundo coerente, em que todos se influenciam mutuamente. Mas este mundo ainda não fez desaparecer os desequilíbrios, alguns dos quais conceituais, em que a relação centro-periferia seria substituída pelo discurso politicamente correto da 'unidade e igualdade'. O que vivemos atualmente é um mundo que busca compensar as fraturas. Para isso são necessários não apenas novos conceitos, mas também pesquisas empíricas concretas no jogo centros-periferias: oportunidades 
educacionais e possibilidades muito díspares de acesso ao capital cultural; idade e gênero; a eficácia dos mercados regionais e globais de capital, bens e trabalho. Quer você tenha nascido europeu, americano ou africano, é tudo menos indiferente. Michael Geyer e Charles Bright escrevem sobre este contexto mundial emergente: "0 mundo em que vivemos tornou-se um globo integrado, mas carece de narrativa e não tem história (...). 0 desafio central de um mundo renovado pela história no final do século 20 é narrar o passado do mundo em uma era de globalidade."

Esta mudança é realmente séria e ainda não muito compreendida. Uma característica específica da globalização, por exemplo, é que ela não assume mais uma forma política reconhecível. Em vez disso, as forças da globalização minam as formas existentes de organização política, por exemplo, por meio da importância das redes de comunicação transnacionais, corporações multinacionais e organizações não governamentais. 0 novo mundo ou história global descreve aqueles fatores que são decisivos para o processo de globalidade hoje. Isso pode, por exemplo, impactar os processos pelos quais novas nações são formadas e Estados tentam se estabelecer (ver p. ex. Sudão do Sul ou as guerras no Cáucaso); ou problemas ambientais; ou doenças como AIDS e SARS, para as quais não há fronteiras nacionais.

As forças globalizantes que atuam sobre os Estados, as economias nacionais e todos os ambientes em que vivemos são enormes, e estamos apenas começando a entendê-las. E isso inclui os horizontes de percepção, os novos fundamentos de sentido e as representações do que o contexto mundial hoje permite, mas também exige cada vez mais.

Por trás de todos esses problemas estão verdadeiros problemas de pesquisa que só podem ser entendidos como globais e que vão além do 'modelo contêiner' das histórias nacionais. De seu profundo conhecimento dos desenvolvimentos históricos mundiais, o historiador William McNeill prediz o amanhecer de uma nova era, ao afirmar que os assuntos humanos estão à beira de uma transformação de longo alcance. A história mundial e global é uma tentativa, essas transformações não apenas para suportar passivamente e agarrar-se a estruturas cognitivas retraídas que não se adaptam mais às condições de hoje, mas para enfrentá-las com a ajuda de novos paradigmas, até porque ficaremos menos expostos a eles e poderemos olhar menos fatalistamente para o futuro.

Pode-se pensar que, após as desconstruções discursivas - através da história das mulheres e de gênero, através da história da vida cotidiana e dos grupos individuais, através da história oral e uma nova história cultural - a narrativa nacional dominante ao longo de várias décadas é questionada "de baixo para cima", voltou o risco de a história mundial e global estar agora fazendo o mesmo "de cima para baixo". No entanto, a história mundial não assinala simplesmente um novo nível acima da historiografia nacional como uma coleção de histórias transnacionais. É um fenômeno novo ou, como os sociólogos o chamam, "emergente". A especificidade dos fenômenos emergentes reside no fato de que eles não podem ser explicados adequadamente com o conhecimento teórico anterior. Se não é possível fazer as novas coisas com as abordagens existentes, para lograr explicações de forma mais adequada, novos esforços teóricos e empíricos são necessários. 
Essa mudança está em curso.

O novo mundo ou história global é uma abordagem que tenta descrever fenômenos que não foram percebidos ou o foram de maneira insuficiente até o momento. 0 fundamentalismo religioso e o novo papel da religião na política em algumas partes do mundo são um exemplo. Quando falamos de fundamentalismo religioso na França e na Europa, geralmente olhamos para o fundamentalismo islâmico. 0 fundamentalismo cristão que determinou a presidência de George W. Bush vem à mente com menos frequência. Quem sabe que as tropas americanas no Iraque foram seguidas não apenas por mercenários privados, mas também por missionários cristãos e que está sendo implementado ali um modelo que lembra fortemente o colonialismo do século 19?

Tendo em vista a necessidade de descrever um mundo globalizado de forma diferente dos conceitos convencionais de narrativas históricas nacionais, porque os fenômenos a serem descritos são historicamente novos, ou seja, novos fatos empíricos estão envolvidos, um aspecto não deve ser esquecido: junto com as discussões sobre a história mundial também deve-se buscar novas sínteses. Isso não é apenas uma reação à fragmentação dos estudos históricos (como nossos mundos da vida prática) nas últimas décadas. Na verdade, a história mundial emergiu da desconstrução de uma história 'objetivista' que se concentra principalmente no nacional, e as relações com as abordagens pós-coloniais, mas também com o gênero ou a história ambiental, que estão claramente presentes. A história mundial não pode ficar para trás nessas abordagens.

\section{História mundial como história do tempo presente.}

A história mundial ou global é sempre história contemporânea no sentido de uma reflexão consciente sobre a própria história e um reposicionamento no contexto mundial. Isso significa: a história mundial e global é principalmente a tentativa de se relacionar com o mundo empírico e também com o imaginado no presente. A história mundial (bem como a discussão dos sociólogos sobre a "sociedade mundial") é baseada na ideia de que há uma dinâmica mundial própria que instaura um horizonte de referência para a interação e a comunicação. Trata-se de um padrão analítico sem o qual a sociedade moderna e sua contingência não poderiam ser adequadamente descritas, interpretadas e explicadas. A história mundial é, portanto, essencialmente uma questão de perspectiva.

0 fato de que a maioria das pessoas na vida prática comum nem mesmo perceba as referências mundiais-sociais e mundiais-históricas em que está imersa não dispensa a importância da questão, mas revela a distância entre a pessoa comum e a consciência histórica necessária para lidar com sua realidade. Se conseguirmos colocar a história em perspectiva em termos de história mundial e promover uma consciência na educação histórica e política que não se feche aos contextos históricos mundiais, se pudermos, portanto, criar uma "mundialização" de nossa história e nossas relações sociais, então teremos adiantado muito a reflexão, e os fenômenos "emergentes" da "sociedade mundial" começariam a se abrir para nós. Como poderia ser uma perspectiva brasileira (ou outra qualquer por esse mundo afora) sobre essa história global é algo 
em que precisamos pensar desde já.

\section{Referências}

CASTELLS, Manuel. A era da informação. Economia, sociedade e cultura. São Paulo; Paz e Terra, 1999-2008.

DINER, Dan. Das Jahrhundert verstehen. Eine universalhistorische Deutung. Munique: Beck; DINER, Dan (2003). Konfliktachsen. Zum historischen Profil des 20. Jahrhunderts, em: Diner, Dan. Gedächtniszeiten, Munique: Beck, 1999, p. 16-31.

DUNN, Ross. Constructing World History in the Classroom. In: Peter Stearns/Peter Seixas/Sam Wineberg (orgs.), Knowing, Teaching and Learning History. National and International Perspectives, Nova York: Berghahn Books, 2000.

GEYER, Michael. World History and General Education: How to Bring the World into the Classroom. In: Hanna Schissler/Yasemin Nohuglu Soysal (orgs.), The Nation, Europe, and the World. Textbooks in Transition. Nova York-Oxford: OUP, 2005, p. 193 - 210.

GEYER, Michael / BRIGHT, Charles. World History in a Global Age. In: The American Historical Review, 100, 1995, p. 1034 - 1060, aqui: p. 1037.

HOBSBAWM, Eric. J. Interesting Times: A Twentieth-Century Life. Londres: Allen Lane, 2002.

HOBSBAWM, Eric. J. Fractured Times: Culture and Society in the 20th Century. Little: Btown, 2013.

HOBSBAWM, Eric J. The Age of Extremes: The Short Twentieth Century, 1914-1991. Nova Iorque: Vintage Books, 1994.

MAIER, Charles. Consigning the 20th Century to History: Alternative Narratives for the Modern Era. The American Historical Review, 105, p. 907 - 931.

MARTINS, Estevão C. de Rezende. História, historiografia e pesquisa em educação histórica. Educar Em Revista (Impresso), 2019, 33v. 35, p. 17-33.

MAZLISH, Bruce. Crossing Boundaries: Ecumenical World, and Global History, em: Philip Pomper/Richard H. Elphick/Richard T. Vann (orgs.). World History. Ideologies, Structures, and Identities. Nova York: Berghahn, 1998, p. 41 - 52, aqui: p. 49.

MCNEILL, William. Th Changing Shape of World History. History and Theory Vol. 34, No. 2, Theme Issue 34: World Historians and Their Critics (Maio, 1995), p. 8-26. 
McNEILL, William. The Culture of the New Capitalism. Yale: Yale University Press (trad. bras. Rio de Janeiro: Record 2006)

NOVICK, Peter. That Noble Dream. The "Objectivity Question" and the American Historical Profession, Cambridge: CUP, 1998.

OSTERHAMMEL, J./PETERSSON, Niels P. Geschichte der Globalisierung. Dimensionen - Prozess Epochen. Beck, Munique, 2003 (5a edição 2012).

OSTERHAMMEL, Jürgen. "Höherer Wahnsinn". Universalhistorische Denkstile im 20. Jahrhundert. In: Horst Walter Blanke/Friedrich Jaeger/Thomas Sandkühler (orgs.). Dimensionen der Historik. Geschichtstheorie, Wissenschaftsgeschichte und Geschichtskultur heute (Festschrift für Jörn Rüsen), Colônia: Böhlau, 1998, p. 277 - 286.

ROSTOW, W. W. The Stages of Economic Growth: A Non-Communist Manifesto. Cambridge: CUP, 1960.

RÜSEN, Jörn. Teoria da História. Uma teoria da Histórica como ciência. Curitiba: Editora da UFPR, 2015.

SENNETT, Richard. A cultura do novo capitalismo. Rio de Janeiro: Record, 2006.

WOBBE, Theresa. Weltgesellschaft. Bielefeld: Transcript-Verlag, 2000.

Artigo Recebido: 30/10/2020

Aprovado em: 25/11/2020

Publicação: Dezembro de 2020 